\title{
THE INTERRELATIONSHIPS BETWEEN GRAIN WEIGHT AND OTHER EAR CHARACTERS IN MAIZE
}

(Received: 7. 6. 2012)

\author{
By \\ M. A. Hager, E. F. El-Hashash, E. I. Zaazaa and W. M. Fares* \\ Agronomy Department, Faculty of Agriculture, Al-Azhar University, Cairo, Egypt. \\ *Central Laboratory for Design \& Statistical Analysis Research, Agricultural Research Center, \\ Giza, Egypt
}

\begin{abstract}
Two field experiments were carried out at the Experimental Farm of Agronomy Department, Faculty of Agriculture, Al-Azhar University, Nasr City, Cairo, Egypt during the two seasons of 2010 and 2011 to evaluate the performance of six maize hybrids (comprising three hybrids from each of single crosses and three-way crosses). The experimental design used was a randomized complete block design with six replications. Four statistical procedures were applied to estimate the relative importance of some grain weight components. The used methods of analysis were simple correlation, multiple linear regression, stepwise multiple linear regression and path analysis. Highly significant and positive association was obtained among all the studied ear traits and grain weight. The results of multiple linear regression model indicated that the ear traits accounted for $79.2 \%$ (expressed as $\mathrm{R}^{2}$ ) of the total variation of grain weight. All ear traits except ear diameter were significantly contributed towards ear grain weight. Considering the model of stepwise multiple linear regression, $75.5 \%$ (expressed as $\mathrm{R}^{2}$ ) of the total variability of ear grain weight were explained by the traits: number of rows/ear, number of kernels / row and 100 kernels weight. The same three traits were also responsible for $80.06 \%$ and $78.33 \%$ of grain weight using full path analysis model and stepwise path analysis model, respectively. Based on the previous results, it could be concluded that the highest ear grain weight of maize would be obtained by selecting breeding materials that have large numbers of rows/ear and kernels /row and heavy weight of 100 kernels.
\end{abstract}

Key words: maize, path coefficients and stepwise path analysis, stepwise regression.

\section{INTRODUCTION}

The world population is expected to increase from its current 6.7 to 8 billion by about 2020 . Since the area of arable land is limited, how to produce more food with limited land resources has been the research focus of domestic and international scholars. Yield of corn (Zea mays L.) is considered as a complex inherited character. Therefore, direct selection for yield per se may not be the most efficient method for its improvement. But indirect selection for other yield related characters could be more effective (Wannows et al., 2010), especially when such traits are closely associated with yield and reflect high heritability estimates.

Information obtained from correlation coefficients among the yield and its related traits could give an initial idea about the more important ones to take in consideration. Breeding decisions built only on the results of correlation coefficient may not always be effective because the simple correlation coefficient measures the mutual association only between a pair of traits neglecting the complex interrelations among all traits (Kang, 1994). Accordingly, the correlations per se may not provide deep image about the importance of each component for determining the variability of grain yield. Wannows et al. (2010) and Khavari Khorasani et al. (2011) reported that highly significant positive correlation values were detected between grain yield/plant and each of ear diameter, ear length, number of grains/row, number of rows/ear and 100 kernels weight.

A path coefficient is a standardized partial regression coefficient, measuring the direct influence of a predictor variable on the response variable. This permits the separation of correlation coefficient into direct effect (path coefficient) and indirect effect (that exerted through other independent variables). Gautam et al. (1999) 
showed that the maximum direct effects towards grain yield were contributed by ear length followed by shelling percentage. Mohammadi et al. (2003) reported that 100 kernel weight and total number of kernels per ear revealed highest direct effects on grain weight/ear $(p=0.74$ and $\mathrm{p}=0.78$, respectively), while ear length, ear diameter, number of rows/ear and number of kernels/row were found to fit as second-order variables. Bahoush and Abbasdokht (2008) mentioned that path analysis revealed that 100 kernel weight exerted maximum positive direct effect on grain yield of maize. The present work aimed to study the relationship between grain weight and its related characters in maize using some statistical procedures namely: simple correlation coefficient, full model regression, stepwise multiple linear regression and path coefficient analysis. The results could be useful to plan an appropriate selection protocol for improving grain yield in maize.

\section{MATERIALS AND METHODS}

Two field experiments were conducted at the Experimental Farm of the Agronomy Department, Faculty of Agriculture, Al-Azhar University, Nasr City, Cairo, Egypt, during the two consecutive seasons of 2010 and 2011 to evaluate some statistical approaches used for estimating the relationships among ear grain weight and its components in maize. The experimental material included three commercial single crosses (30k08, 30k09 and Bashair), and three of three-way crosses (Giza 311, Giza 323 and Giza 324). The experimental design used was a randomized complete block design with six replicates. The plot area was $17.5 \mathrm{~m}^{2}$ including 5 ridges, each of $5 \mathrm{~m}$ long and $0.7 \mathrm{~m}$ wide. Cultural practices were maintained at the recommended levels to satisfy maximum grain yield. At harvest, to obtain more reliable results, a large sample size consisting of 30 ears was randomly chosen from each plot to record the data of following seven ear traits:

1. Number of rows / ear (NRE). $\left(\mathrm{X}_{1}\right)$.

2. Number of kernels / row (NKR). $\left(X_{2}\right)$.

3. Ear length $(\mathrm{EL})$ in $\mathrm{cm} .\left(\mathrm{X}_{3}\right)$.

4. Ear diameter $(\mathrm{ED})$ in $\mathrm{cm} .\left(\mathrm{X}_{4}\right)$.

5. 100 kernel weight $(100 \mathrm{KW}) \mathrm{gm} .\left(\mathrm{X}_{5}\right)$.

6. Shelling percentage $(\mathrm{SP} \%) .\left(\mathrm{X}_{6}\right)$.

7. Ear grain weight $(\mathrm{EGW}) \mathrm{gm} .(\mathrm{Y})$

\section{Statistical procedures}

Four statistical procedures, differing in their mathematical concept; target and final output, were separately evaluated to explore the relationships among ear grain weight and its components in maize. The used models are summarized as follows:

1. Simple correlation: matrix of simple correlation coefficient between ear grain weight and each of other ear traits, computed as outlined by Steel and Torrie (1980).

2. Path analysis: the methodology proposed by Dewey and $\mathrm{Lu}$ (1959) was followed to partition the simple correlation coefficient of the previous step into direct and indirect effects using two models of analysis ; full model and stepwise path analyses models. The first model takes in consideration all studied ear traits as components of ear grain weight while the second model concentrated on the most important ear traits as a result of stepwise multiple linear regression model.

3. Multiple linear regressions: full model regression was estimated according to Draper and Smith (1981) using ear grain weight as a resultant variable and its related ear traits as explanatory variables.

4. Stepwise multiple linear regression: this model was applied according to Draper and Smith (1981) to determine the variables that accounted for the majority of the total ear grain weight variability. To avoid the lack of fit of both full model regression and stepwise multiple linear regression as a result of multicollinearity problem (the strong association among ear traits), the level of multicollinearity was estimated using a common measure namely: Variance Inflation Factor (VIF) as suggested by Hair et al. (1992). Large VIF values (above 10) reported high collinearity causing a rejected model.

\section{RESULTS AND DISCUSSION}

The basic descriptive statistics for the studied ear traits are shown in Table (1). It is noted that the estimates of coefficient of variation ( $\mathrm{CV} \%)$ were located at the statistically acceptable limits for each character.

\subsection{Correlation matrix}

The simple correlation coefficients among all the studied traits are shown in Table (2). The results revealed that all the studied ear traits had highly significant and positive association with grain weight. The greatest correlation coefficients were recorded between grain weight and each of the number of kernels / row $\left(0.648^{* *}\right)$ and ear length $\left(0.619^{* *}\right)$. This result could help the 
Table (1): Basic descriptive statistics for the seven ear traits, over the two seasons.

\begin{tabular}{|l|c|c|c|c|c|}
\hline \multirow{2}{*}{ Ear traits } & \multicolumn{5}{|c|}{ Descriptive statistics } \\
\cline { 2 - 6 } & Mean & SD & CV \% & Mini. value & Maxi. value \\
\hline No. rows/ear & 12.89 & $\mathbf{0 . 8 8}$ & $\mathbf{6 . 8 0}$ & 10.00 & $\mathbf{1 6 . 0 0}$ \\
\hline No. kernels/row & $\mathbf{4 0 . 4 0}$ & $\mathbf{3 . 2 5}$ & $\mathbf{8 . 0 4}$ & $\mathbf{3 0 . 0 0}$ & 48.00 \\
\hline Ear length, cm & 18.43 & 1.59 & $\mathbf{8 . 6 1}$ & 13.50 & $\mathbf{2 2 . 0 0}$ \\
\hline Ear diameter, cm & 3.30 & $\mathbf{0 . 3 7}$ & 11.21 & $\mathbf{2 . 2 0}$ & 4.10 \\
\hline 100 kernel weight,gm & $\mathbf{3 0 . 9}$ & $\mathbf{2 . 9 0}$ & $\mathbf{9 . 3 9}$ & $\mathbf{2 3 . 2 7}$ & $\mathbf{4 3 . 2 4}$ \\
\hline Shelling \% & $\mathbf{0 . 8 5}$ & $\mathbf{0 . 0 3}$ & $\mathbf{3 . 0 7}$ & $\mathbf{0 . 7 9}$ & $\mathbf{0 . 9 3}$ \\
\hline Ear grain weight,gm & 141.73 & $\mathbf{2 1 . 8 9}$ & $\mathbf{1 5 . 4 4}$ & $\mathbf{9 9 . 0 0}$ & $\mathbf{1 8 4 . 4 4}$ \\
\hline
\end{tabular}

Table (2): Matrix of simple correlation coefficients among ear grain weight and its components in maize over 2010 and 2011 seasons.

\begin{tabular}{|l|c|c|c|c|c|c|c|}
\hline \multicolumn{1}{|c|}{ Traits } & NRE & NKR & EL & ED & $100 K W$ & SP & EGW \\
\hline No. of rows / ear (NRE) & 1 & -0.141 & 0.018 & $0.327^{* *}$ & 0.043 & $-\mathbf{0 . 0 1 1}$ & $0.318^{* *}$ \\
\hline No. of kernels / row (NKR) & & 1 & $0.703^{* *}$ & 0.218 & 0.214 & $0.453^{* *}$ & $0.648^{* *}$ \\
\hline Ear length (EL) & & & 1 & $0.351^{* *}$ & $\mathbf{0 . 4 1 5} * *$ & $0.255^{*}$ & $0.619^{* *}$ \\
\hline Ear diameter (ED) & & & & 1 & 0.095 & 0.041 & $0.398^{* *}$ \\
\hline 100 kernel weight (100KW) & & & & & 1 & $0.417^{* *}$ & $\mathbf{0 . 5 6 3} * *$ \\
\hline Shelling percentage (SP) & & & & & & 1 & $0.566^{* *}$ \\
\hline Ear grain weight (EGW) & & & & & & & 1 \\
\hline
\end{tabular}

* and ** significant at 0.05 and 0.01 probability levels, respectively.

breeder to select high ear grain weight for one or more of these traits.

On the other hand, the studied ear traits exhibited important trends of association among themselves. Positive and highly significant correlation was found between the number of rows/ ear and ear diameter $\left(0.327^{* *}\right)$. The correlation between the number of kernels/row and each of the ear length $\left(0.703^{* *}\right)$ and shelling percentage $\left(0.453^{* *}\right)$ was found to be positive and highly significant. Also, highly significant and positive correlation coefficient was observed between ear length and each of ear diameter $\left(0.351^{* *}\right)$ and 100 kernel weight $\left(0.415^{* *}\right)$, while the shelling percentage had only significant positive association with ear length $\left(0.255^{*}\right)$. Furthermore, positive and highly significant correlation was detected between 100 grain weight and shelling percentage $(0.417 * *)$. The correlation coefficients among the other traits were insignificant.
Accordingly, maize breeders must take interest in the interrelationships among ear traits when planning the breeding program. Mohamed and Sedhom (1993), Mohamed (2004), El- Taweel and Barakat (2006), Saidaiah et al. (2008) and Khodarahmpour and Hamidi (2012) stated that the correlation coefficients between grain yield and most ear traits were positive and significant.

It is worthwhile to remember that large sample size of data may be a main reason of the highly significance of some small values of correlation coefficients.

\subsection{Multiple linear regression analysis}

Data presented in Table (3) show the partial regression coefficients and their corresponding probability levels of the ear traits in predicting the ear grain weight using full model regression. The prediction equation was formulated as follows: $\mathrm{EKW}=-349.8+8.21(\mathrm{NRE})+3.18(\mathrm{NKR})+0.65$ $(\mathrm{EL})+7.78(\mathrm{ED})+2.51(100 \mathrm{KW})+167.97(\mathrm{SP})$.

In addition to the high significance of the used 
Table (3): Multiple linear regression model to explain grain weight variation using some of its related characters.

\begin{tabular}{|c|c|c|c|c|}
\hline Characters & $\begin{array}{l}\text { Regression } \\
\text { coefficient } \\
\text { (b) }\end{array}$ & $\begin{array}{l}\text { Standard } \\
\text { error }(\mathrm{SE})\end{array}$ & $\begin{array}{l}\text { Probability } \\
\text { level } \quad(P- \\
\text { value) }\end{array}$ & $\begin{array}{l}\text { Variance } \\
\text { inflation } \\
\text { factor (VIF) }\end{array}$ \\
\hline No. of rows / ear (NRE) & $8.213 * *$ & 1.546 & 000 & 1.20 \\
\hline No. of kernels / row (NKR) & $3.176 * *$ & 0.631 & 000 & 2.38 \\
\hline Ear length (EL) & 0.647 & 1.288 & 0.617 & 2.727 \\
\hline Ear diameter $(\mathrm{ED})$ & 7.778* & 3.82 & 0.046 & 1.303 \\
\hline 100 kernel weight $(100 \mathrm{KW})$ & $2.508 * *$ & 0.5271 & 000 & 1.527 \\
\hline Shelling percentage (SP) & $167.97 * *$ & 60.13 & 0.007 & 1.594 \\
\hline Intercept & -349.8 & & & \\
\hline $\begin{array}{l}\text { Model sig. } \\
\mathbf{R}^{2} \\
\text { Adjusted } \mathbf{R}^{2}\end{array}$ & $\begin{array}{l}000 \\
79.2 \\
77.3\end{array}$ & & & \\
\hline
\end{tabular}

model ( $\mathrm{p}$ value $<0.01$ ), it successfully explained $79.2 \%$ of the total variation of grain weight expressed as $\mathrm{R}^{2}$. The residual content $\left(1-\mathrm{R}^{2}=\right.$ $20.8 \%$ ) may be attributed to unknown variation (random error), human error during measuring the studied traits, and/or some other traits that were not included in the present investigation. The obtained results reported that the traits of number of rows / ear, number of kernels / row, ear diameter, 100 kernel weight and shelling percentage were significantly contributed towards ear grain weight while the ear length was not.

Concerning the goodness of fit of the used model, it is noted that the values of VIF for all the studied traits were less than 10 suggesting that multicollinearity problem is not a serious issue (Judge et al., 1988). Also, the value of the adjusted $R^{2}$ (82.7) was very close to the $R^{2}(85.3)$ which considered an indication of the optimum sample size and the goodness of fit for the used model.

3.3. Stepwise multiple linear regression analysis

This method was used to determine the more effective ear traits that mostly explained the variation of grain weight. The results of Table (4) show the partial regression coefficient as well as their significance for the accepted limiting three variables that are significantly contributing to the variation of ear grain weight. These variables were number of rows / ear, number of kernels / row and 100 Kernel weight. According to the results, 75.5 $\%$ (expressed as $\mathrm{R}^{2}$ ) of the total variation in ear grain weight could be attributed to these aforementioned three traits. The other three traits were not included in the model due to their very low relative contribution.

The prediction equation for grain weight using the accepted three traits was formulated as follows:

$$
\begin{gathered}
\mathrm{EKW}=-246.78+9.67(\mathrm{NRE})+4.14(\mathrm{NKR})+ \\
3.13(100 \mathrm{KW}) .
\end{gathered}
$$

On the other hand, the validity of the proposed model was established where the VIF values for the accepted traits were less than 10 indicating no harmful effect of multicollinearity. Also, the adjusted $R^{2}$ value (74.4) was very near to its corresponding $R^{2}$ value (75.5) indicating the goodness of fit of the used model. As mentioned before, the number of rows / ear, the number of kernels / row and 100 kernels weight were the most important variables according to stepwise regression model. Therefore, these three traits have to be ranked the first in the breeding programs for improving ear grain weight in maize. The current results of full model regression and stepwise multiple linear regression are in harmony with those obtained by Shafshak et al. (1989) and (2009), and Khodarahmpour and Hamidi (2012).

\subsection{Path analysis}

Information obtained from simple correlation coefficient can be enlarged by partitioning it into direct and indirect effects for a given set of causal interrelationships. 
Table (4): Regression parameters of the accepted variables according to stepwise multiple linear regression.

\begin{tabular}{|l|c|c|c|c|}
\hline Characters & $\begin{array}{c}\text { Reg. Parameters } \\
\text { Regression } \\
\text { coefficient (b) }\end{array}$ & $\begin{array}{c}\text { Standard } \\
\text { error (SE) }\end{array}$ & $\begin{array}{c}\text { Probability } \\
\text { level (P-value) }\end{array}$ & $\begin{array}{c}\text { Variance } \\
\text { inflation factor } \\
\text { (VIF) }\end{array}$ \\
\hline No. of rows / ear (NRE) & $\mathbf{9 . 6 7 * *}$ & 1.517 & $\mathbf{0 0 0}$ & $\mathbf{1 . 0 2 6}$ \\
\hline No. of kernel / row (NKR) & $4.138^{* *}$ & $\mathbf{0 . 4 1 9}$ & $\mathbf{0 0 0}$ & $\mathbf{1 . 0 7 3}$ \\
\hline 100 kernel weight (100KW) & $\mathbf{3 . 1 2 8 * *}$ & $\mathbf{0 . 4 6 4}$ & $\mathbf{0 0 0}$ & $\mathbf{1 . 0 5 4}$ \\
\hline Intercept & $\mathbf{- 2 4 6 . 7 8}$ & & & \\
\hline Model sig. & $\mathbf{0 0 0}$ & & & \\
\hline $\mathbf{R}^{2}$ & 75.5 & & & \\
\hline Adjusted $\mathbf{R}^{2}$ & 74.4 & & & \\
\hline
\end{tabular}

Table (5): Full model path analysis (direct and joint effects) of ear grain yield and its related characters in maize.

\begin{tabular}{|l|c|c|c|c|c|c|c|}
\hline \multicolumn{1}{|c|}{ Characters } & NRE & NKR & EL & ED & $100 K W$ & SP & $\mathbf{r}_{\text {xy }}$ \\
\hline No. of rows / ear (NRE) & $\underline{\mathbf{0 . 3 2 8}}$ & $\mathbf{- 0 . 0 6 7}$ & $\mathbf{0 . 0 0 0 8}$ & $\mathbf{0 . 0 4 2 3}$ & $\mathbf{0 . 0 1 5}$ & $\mathbf{- 0 . 0 0 1 6}$ & $\mathbf{0 . 3 1 8} * *$ \\
\hline No. of kernels / row (NKR) & $\mathbf{- 0 . 0 4 6}$ & $\underline{\mathbf{0 . 4 7 8}}$ & $\mathbf{0 . 0 3 3}$ & $\mathbf{0 . 0 2 8}$ & $\mathbf{0 . 0 7 5 7}$ & $\mathbf{0 . 0 7 9}$ & $\mathbf{0 . 6 4 8} * *$ \\
\hline Ear length (EL) & $\mathbf{0 . 0 0 6}$ & $\mathbf{0 . 3 3 6}$ & $\underline{\mathbf{0 . 0 4 7}}$ & $\mathbf{0 . 0 4 6}$ & $\mathbf{0 . 1 4 7}$ & $\mathbf{0 . 0 3 7}$ & $\mathbf{0 . 6 1 9} * *$ \\
\hline Ear diameter (ED) & $\mathbf{0 . 1 0 7}$ & $\mathbf{0 . 1 0 4}$ & $\mathbf{0 . 0 1 7}$ & $\underline{\mathbf{0 . 1 3 0 2}}$ & $\mathbf{0 . 0 3 3 6}$ & $\mathbf{0 . 0 0 5 9}$ & $\mathbf{0 . 3 9 8} * *$ \\
\hline 100 kernel weight (100KW) & $\mathbf{0 . 0 1 4}$ & $\mathbf{0 . 1 0 2}$ & $\mathbf{0 . 0 1 9 6}$ & $\mathbf{0 . 0 1 2 4}$ & $\underline{\mathbf{0 . 3 5 4}}$ & $\mathbf{0 . 0 6 0 4}$ & $\mathbf{0 . 5 6 3} * *$ \\
\hline Shelling percentage (SP) & $\mathbf{- 0 . 0 0 3 6}$ & $\mathbf{0 . 2 5 9 7}$ & $\mathbf{0 . 0 1 2 1}$ & $\mathbf{0 . 0 0 5 3}$ & $\mathbf{0 . 1 4 7 7}$ & $\underline{\mathbf{0 . 1 4 4 9}}$ & $\mathbf{0 . 5 6 6} * *$ \\
\hline
\end{tabular}

- Residual effect $=0.4725$

Table (6): Stepwise path analysis (direct and joint effects) of ear weight yield and its related characters in maize.

\begin{tabular}{|l|c|c|c|c|}
\hline \multicolumn{1}{|c|}{ Characters } & NRE & NKR & $100 K W$ & $\mathbf{r}_{\mathrm{xy}}$ \\
\hline No. of rows / ear (NRE) & $\underline{\mathbf{0 . 3 8 7}}$ & $\mathbf{- 0 . 0 8 7}$ & $\mathbf{0 . 0 1 7}$ & $\mathbf{0 . 3 1 8} * *$ \\
\hline No. of kernels / row (NKR) & $\mathbf{- 0 . 0 5 5}$ & $\underline{\mathbf{0 . 6 1 4}}$ & $\mathbf{0 . 0 8 9}$ & $\mathbf{0 . 6 4 8} * *$ \\
\hline 100 kernels weight (100KW) & $\mathbf{0 . 1 3 1}$ & $\mathbf{0 . 0 1 7}$ & $\underline{\mathbf{0 . 4 1 5}}$ & $\mathbf{0 . 5 6 3} * *$ \\
\hline
\end{tabular}

- Residual effect $=0.496 \quad$ - The direct effects occupied the diagonal cells (bold and underlined).

Considering the path analysis based on all the studied ear traits (full model), the matrix of direct and joint effects is shown in Table (5). The maximum direct effect was obtained for the number of kernels / row (0.478), followed by 100 kernels weight (0.354) and the number of rows / ear (0.328). On the other hand, the previous three traits recorded small indirect effect values through the other traits. In another words, the indirect effects of the three traits were less important compared to their corresponding direct effects. In accordance, the high positive direct effects for number of kernels / row, 100 kernels weight and number of rows / ear in addition to their highly significant coefficients of correlation are evidence that the indirect selection through these traits would be effective for improving ear grain weight in maize.

In contrast, although highly significant positive coefficients of correlation were recorded between ear grain weight and each of ear length, ear diameter and shelling percentage, the direct effects for these traits were very small. This result may be returned to that path analysis separate the indirect effects from the simple correlation coefficient where the indirect effect values for the preceding three traits were more considerable compared to their direct effects. The highest indirect effects values for ear length and shelling percentage on ear grain weight were observed through each of 


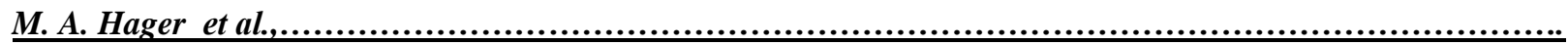

Table (7): The coefficient of determination (CD) and relative importance (RI \%) of ear grain weight components in maize, according to full and stepwise path analysis.

\begin{tabular}{|c|c|c|c|c|c|}
\hline \multirow{2}{*}{\multicolumn{2}{|c|}{ Characters }} & \multicolumn{2}{|c|}{ Full model path analysis } & \multicolumn{2}{|c|}{ Stepwise path analysis } \\
\hline & & CD & RI \% & CD & RI \% \\
\hline \multicolumn{6}{|c|}{ Direct effects } \\
\hline \multicolumn{2}{|c|}{ No of rows / ear (NRE) } & 0.108 & 9.91 & 0.1495 & 13.1875 \\
\hline \multicolumn{2}{|c|}{ No of kernels / row (NKR) } & 0.229 & 21.01 & 0.3766 & 33.2174 \\
\hline \multicolumn{2}{|c|}{100 kernels weight $(100 \mathrm{KW})$} & 0.125 & 11.47 & 0.1722 & 15.1924 \\
\hline \multicolumn{2}{|c|}{ Ear length (EL) } & 0.0022 & 0.20 & & \\
\hline \multicolumn{2}{|c|}{ Ear diameter (ED) } & 0.0169 & 1.55 & & \\
\hline \multicolumn{2}{|c|}{ Shelling percentage (SP) } & 0.0209 & 1.92 & & \\
\hline \multicolumn{6}{|c|}{ Indirect effects } \\
\hline \multirow{5}{*}{ NRE via } & NKR & -0.044 & 4.04 & -0.0669 & 5.902 \\
\hline & $100 \mathrm{KW}$ & 0.010 & 0.92 & 0.0138 & 1.217 \\
\hline & EL & 0.0006 & 0.06 & & \\
\hline & ED & 0.028 & 2.57 & & \\
\hline & SP & -0.001 & 0.09 & & \\
\hline \multirow{4}{*}{ NKR via } & $100 \mathrm{KW}$ & 0.072 & $\underline{6.61}$ & 0.109 & 9.6147 \\
\hline & EL & 0.038 & 3.49 & & \\
\hline & ED & 0.027 & 2.48 & & \\
\hline & SP & 0.075 & 6.88 & & \\
\hline \multirow{3}{*}{$\begin{array}{c}100 \mathrm{KW} \\
\text { via }\end{array}$} & EL & 0.014 & $\overline{1.28}$ & & \\
\hline & ED & 0.009 & 0.83 & & \\
\hline & SP & 0.043 & 3.94 & & \\
\hline \multirow{2}{*}{ EL via } & ED & 0.004 & $\overline{0.37}$ & & \\
\hline & SP & 0.003 & 0.28 & & \\
\hline ED via & SP & 0.002 & 0.18 & & \\
\hline \multicolumn{2}{|c|}{ Total (direct + indirect) } & 0.78 & 80.06 & 0.7544 & 78.332 \\
\hline \multicolumn{2}{|c|}{ Residuals } & 0.22 & 19.94 & 0.2456 & 21.668 \\
\hline \multicolumn{2}{|c|}{ Total } & 1.000 & 100 & 1.00 & 100 \\
\hline
\end{tabular}

Note: Bold and underlined cells indicate the highest values of direct and indirect effects.

number of kernel / rows and 100 kernels weight recording (0.336 and 0.146$)$ for ear length and (0.26 and 0.148) for shelling percentage, respectively.

Considering ear diameter, the important part of its indirect effects were observed through each of number of rows / ear (0.107) and number of kernels / row (0.104).

Because stepwise multiple linear regression models determine the ear traits that mostly reflected the total variation of ear grain weight, some researchers prefer to use only the traits selected by stepwise regression model in path analysis. The matrix of direct and indirect effects using stepwise path analysis is presented in Table (6). These results are exactly in parallel line with those obtained by full model of path analysis where the highest direct effect was recorded via number of kernels / row (0.614) followed by 100 kernels weight $(0.415)$ and number of rows / ear (0.389). Moreover, the values of their indirect effects were trivial through each other. The current findings are consistent with Gautam et al., (1999), Kumar and Kumar (2000), Mohen et al., (2002), Bello et al., (2009) and Wannows et al., (2010).

The coefficient of determination (CD) and relative importance (RI \%), using both of path analysis as a full model and stepwise model, are shown in Table (7). The results revealed that the greatest part of grain weight was explained by the direct effect of the number of kernels / row (21.01 and 33.22), followed by 100 kernels weight (11.47 and 15.19) and the number of rows / ear (9.91 and 13.19) for the two types of path analysis, respectively. The great contribution of these traits 
on ear grain weight supported their importance as selection criteria in maize breeding programs.

According to the relative importance of the joint effects, it appeared that the highest values were recorded for the indirect effect of the the number of rows / ear on grain weight through its associations with the number of grains / row (4.04 and 5.90) followed by the joint effect of number of grains / row via 100 kernel weight (6.61 and 9.61) for the two types of path analysis (full model and stepwise model), respectively. In addition, the full model of path analysis recorded other important indirect effects, such as, that recorded for number of kernels / row through both of ear length (3.49) and shelling percentage (6.88), and the indirect effects of 100 kernels weight via shelling percentage (3.94). Ineffective values of relative importance were obtained by the other direct and indirect effects. Totally, the studied traits accounted for $80.06 \%$ of the ear grain weight variation using full model path analysis while only $78.33 \%$ was the explained part by stepwise path analysis.

Although, the two models of path analysis partially showed similar trends the authors appreciated to use full model path analysis because it included all the studied traits and consequently gave more information compared to the other model. The current results are in accordance with those observed by Mohamadi et al. (2003) and Rafiq et al. (2010).

The use of various statistical models by plant breeders or agronomists presents the potential of increasing the comprehension of the causal relationships among traits and can help to determine the nature and sequence of traits to be selected in a breeding program.

Finally, from the current investigation, it could be recommended that the important ear traits, overall the used statistical procedures, were the number of rows / ear, number of kernels / row and 100 kernels weight. These traits would enable the breeders to realize higher yielding hybrids of maize.

\section{REFERENCES}

Bahoush M. and Abbasdokht, H. (2008). Correlation coefficient analysis between grain yield and its components in corn (Zea mays L.) hybrids. International Meeting on Soil Fertility Land Management and Agroclimatology., Turkey, 2008. p:263 - 265.

Bello O. B., Abdulmaliq S. Y., Afolabi M. S. and Ige S. A. (2009). Correlation and path coefficient analysis of yield and agronomic characters among open pollinated maize varieties and their $F_{1}$ hybrids in a diallel cross. African Journal of Biotechnology Vol. 9 (18), pp. $2633-2639$.

Dewey J. R. and Lu K. H. (1959). A correlation and path coefficient analysis of components of crested wheat grass seed production. Agron. J. (51):515-518.

Draper N. R. and Smith H. (1981). Applied Regression Analysis. John Wiley \& Sons Inc., New York.

El-Taweel A. M. S. A. and Barakat Somia A. (2006). Statistical studies on designed and uniformity trials to detect the interrelation among yield and its component in maize, Egypt. J. Plant Breed. 10(2): 65-78.

Gautam A. S., Mittal R. K. and Bhandari J. C. (1999). Correlations and path coefficient analysis in maize (Zay mays L.). Annals Agric. Bio. Research, 4 (2): 169-171.

Hair J. F., Anderson J. R., Tatham R. L. and Black W. C. (1992). Multivariate Data Analysis. MacMillan Pub. Comp., A division of MacMillan, Inc.

Judge G. G., Hill R. C., Griffiths W. E., Lutkepohl H. and Lee T.C. (1988). Introduction to the Theory and Practice of Econometrics, $2^{\text {nd }}$ ed. New York: John Wiley and Sons.

Kang M. S. (1994). Applied Quantitative Genetics. M.S. Kang Publisher, Baton Rouge, LA.

Khavari Khorasani S., Mostafavi Kh., Zandipour E. and Heidarian A. (2011). Multivariate analysis of agronomic traits of new corn hybrids (Zea mays L.). International Journal of AgriScience, 1(6): 314 - 322.

Khodarahmpour Z. and Hamidi J. (2012). Study of yield and yield components of corn (Zea mays L.) inbred lines to drought stress. African J. of Biot., 11(13), pp. 3099 - 3105.

Kumar M. V. N. and Kumar S. S. (2000). Studies on character association and path coefficient for grain yield and oil content in maize. Annals Agric. Research, 21(1): 73-78.

Mohamed M. K. and Sedhom S. A. (1993). A comparison between four statistical procedures of relating yield components in a set of corn varieties. Annals Agric. Sci., Moshtohor, 31(4): 1856-1865.

Mohamed N. A. (2004). Principal component and response curve analysis of some maize hybrids to different levels and plant density. Bull. Fac. Agric., Cairo Univ., (55): 531-556. 
Mohammadi S. A., Prasanna B. M. and Singh N. N. (2003). Sequential path model for determining interrelationships among grain yield and related characters in maize. Crop Sci., (43):1690-1697.

Mohen Y. C., Singh D. K. and Rao N. V. (2002). Path coefficient analysis for oil and grain yield in maize (Zea mays L.) genotypes. Nation. J. Plant Improv., 4(1): 75-76.

Rafiq C. M., Rafique M., Hussain A. and Altaf M. (2010). Studies on heritability, correlation and path analysis in maize (Zea mays L.). J. Agric. Res., 48(1): 35 - 38.

Saidaiah P., Satyanarayana E. and Kumar S.S. (2008). Association and path coefficient analysis in maize (Zea mays L.). Agric. Sci. Digest, 28 (2) : $79-83$.
Shafshak S.E., Abd- El Halim A. A., Saad A. M. M. and Ahamed, F. A. (1989). Integrated regression analysis of maize yield factor using minimum sample size. Egypt. J. Appl. Sci., 4: 1855-1866.

Shafshak S.E., Sedhom S. A., Nasr S. M. and Fateh Hayam S. A. (2009). Determination of the relative contribution for yield factors in maize by using some statistical procedures. Annals Agric. Bio. Research, 4(2): 169-171.

Steel R. G. D. and Torrie, J. H. (1980). Principles and Procedures of Statistics: A Biometrical Approach, $2^{\text {nd }}$ edition. McGraw-Hill., Tokyo.

Wannows A. A., Azzam H. K. and Al-Ahmad S. A. (2010). Genetic variances, heritability, correlation and path coefficient analysis in yellow maize crosses (Zea mays L.). Agric. Biol. J. N. Am., 1(4): $630-637$.

\title{
العلاقات المتداخلة بين وزن حبوب الكوز وبعض صفات الكوز الأخرى فى الأرة الثامية \\ محمه احمد هاجر - عصام فتحى الحشاش - عز الدين ابراهيم زعزع -* وليد محمد فارس

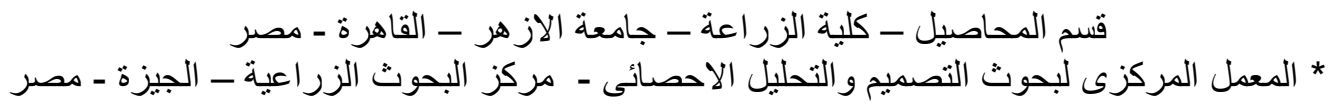

\begin{abstract}
ملخص الك

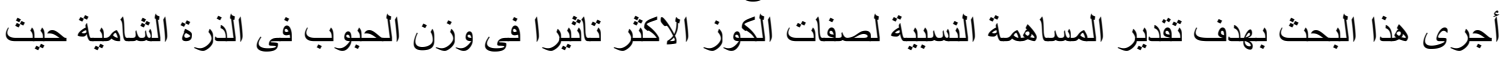

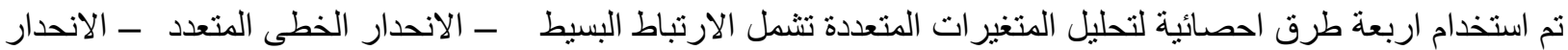

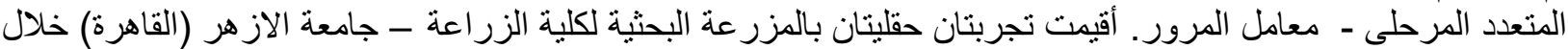

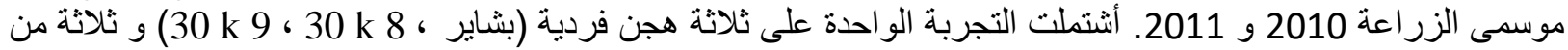

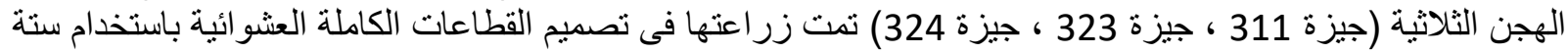

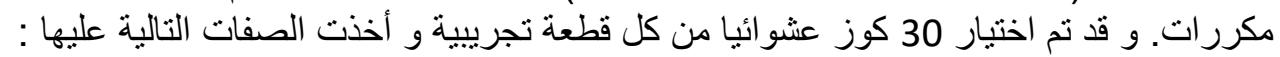

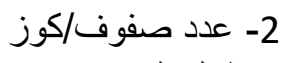
4- 2 - طول الكوز (سم)

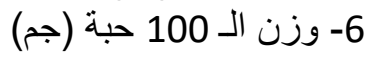

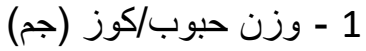
3- عدد حبوب/صف

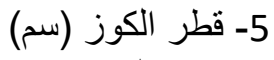

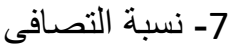

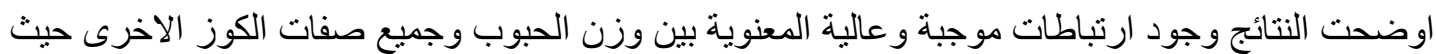

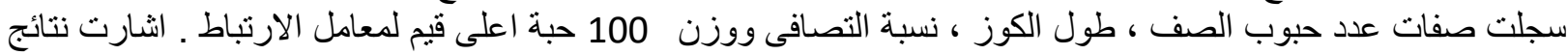

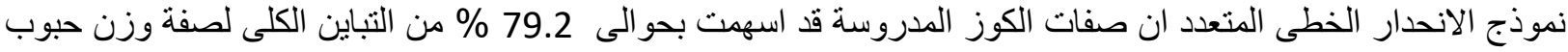

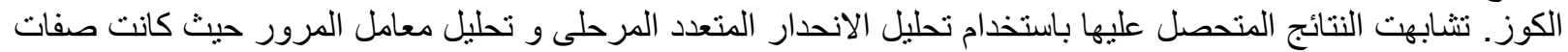

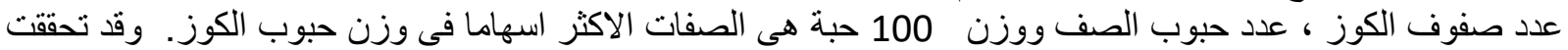

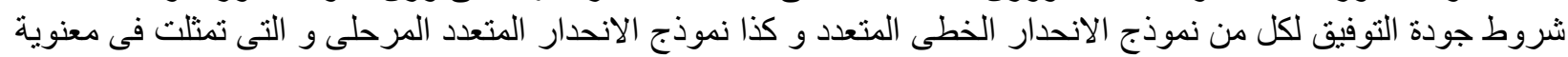

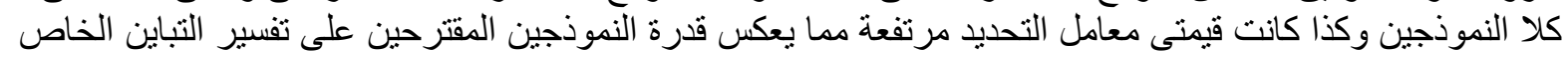

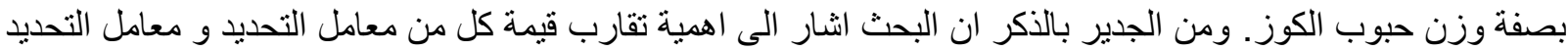

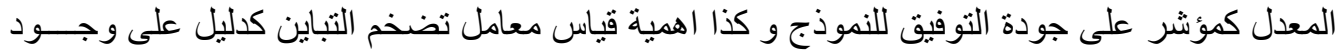




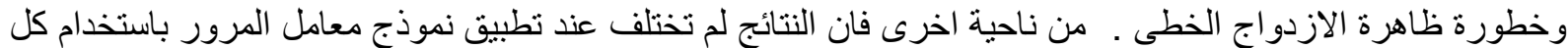

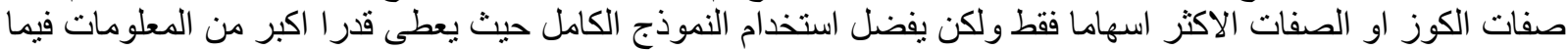

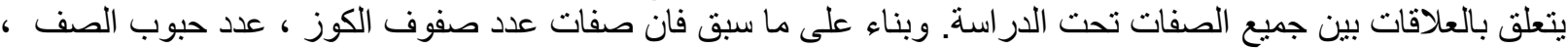

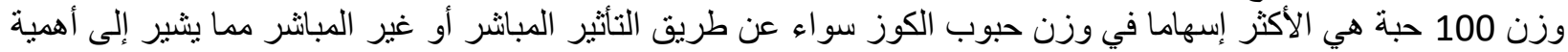

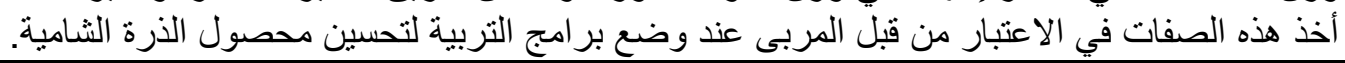

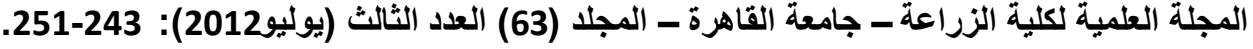

